\title{
CONF-9710103-
}

\section{DISSOLUTION OF ORNL HLW SLUDGE AND PARTITIONING OF THE ACTINIDES USING THE TRUEX PROCESS*}

\author{
Barry B. Spencer \\ Robotics \& Process Systems Division \\ Oak Ridge National Laboratory \\ Oak Ridge, Tennessee 37831 \\ B. Z. Egan \\ E. C. Beahm \\ C. W. Chase \\ and \\ T. A. Dillow \\ Chemical Technology Division \\ Oak Ridge National Laboratory \\ Oak Ridge, Tennessee 37831 \\ Paper for Presentation \\ at the \\ Tenth Symposium on \\ Separation Science and Technology for Energy Applications \\ October 20-24, 1997 \\ and for Publication in \\ Separation Science and Technology
}

\begin{abstract}
The submitted manuscript has been authored by a contractor of 'the U.S. Government under contract No. DE-ACOSS6OF22464. Accordingly, the U.S. Government retains a paidup, nonexclusive irrevocable, worldwide license to publish or reproduce the published form of this contribution, prepare derivative works, distribute copies to the public, and perform publicly and display publicly, or allow others to do so, for U.S.

Govemment purposes."
\end{abstract}

Research sponsored by the Office of Science and Technology-Tank Focus Area for the U.S. Department of Energy under Contract No. DE-AC05-960R22464 with Oak Ridge National Laboratory, managed by Lockheed Martin Energy Research Corp. 


\section{DISCLAIMER}

This report was prepared as an account of work sponsored by an agency of the United States Government. Neither the United States Government nor any agency thereof, nor any of their employees, make any warranty, express or implied, or assumes any legal liability or responsibility for the accuracy, completeness, or usefulness of any information, apparatus, product, or process disclosed, or represents that its use would not infringe privately owned rights. Reference herein to any specific commercial product, process, or service by trade name, trademark, manufacturer, or otherwise does not necessarily constitute or imply its endorsement, recommendation, or favoring by the United States Government or any agency thereof. The views and opinions of authors expressed herein do not necessarily state or reflect those of the United States Government or any agency thereof. 


\section{DISCLAMIER}

Portions of this document may be illegible in electronic image prodnets. Images are produced from the best available osigion doerment. 


\title{
DISSOLUTION OF ORNL HLW SLUDGE AND PARTITIONING OF THE ACTINIDES USING THE TRUEX PROCESS
}

\author{
Barry B. Spencer \\ Robotics \& Process Systems Division \\ Oak Ridge National Laboratory \\ Oak Ridge, Tennessee 37831 \\ B. Z. Egan \\ E. C. Beahm \\ C. W. Chase \\ and \\ T. A. Dillow \\ Chemical Technology Division \\ Oak Ridge National Laboratory \\ Oak Ridge, Tennessee 37831
}

Keywords: waste, sludge, treatment, extraction, TRUEX

Abstract

Experiments were conducted to evaluate the transuranium extraction (TRUEX) process for partitioning actinides from actual dissolved high-level radioactive waste (HLW) sludge. All tests were performed at a temperature of $24^{\circ} \mathrm{C}$. Dissolution of the sludge prior to the extraction tests provided the opportunity to evaluate the dissolution process.

Samples of sludge from Melton Valley Storage Tank (MVST) W-25 were rinsed with mild caustic $(0.2 \mathrm{MNaOH})$ to reduce the concentrations of nitrates and fission products associated with the interstitial liquid. In one campaign the rinsed sludge was leached in nitric acid, and about $50 \%$ of the dry mass of the sludge was dissolved. The resulting solution contained total metal concentrations of $\sim 1.8 \mathrm{M}$ with a nitric acid concentration of $2.9 \mathrm{M}$. The solution began gelling immediately and a visible gel layer was observed after 8 days. In the other campaign the sludge was neutralized with nitric acid to destroy the carbonates, then leached with $2.6 \mathrm{MNaOH}$ for $\sim 6 \mathrm{~h}$ before rinsing with the mild caustic. The sludge was then leached in nitric acid, and about $80 \%$ of the sludge dissolved. The resulting solution contained total metal concentrations of $\sim 0.6 \mathrm{M}$ with a nitric acid concentration of $1.7 \mathrm{M}$. This solution became hazy in $\sim 8$ days, indicating gel formation, but did not display separated gel layers after aging 20 days. 
Batch liquid-liquid equilibrium tests of both the extraction and stripping operations were conducted. Chemical analyses of both phases were used to evaluate the process. Evaluation was based on two metrics: the fraction of TRU elements removed from the dissolved sludge and comparison of the results with predictions made with the Generic TRUEX Model (GTM). The fractions of $\mathrm{Eu}, \mathrm{Pu}, \mathrm{Cm}$, Th and $\mathrm{U}$ species removed from aqueous solution in only one extraction stage were $>95 \%$ and were close to the values predicted by the GTM. Mercury was also found to be strongly extracted, with a one-stage removal of $>92 \%$. In one test, vanadium appeared to be moderately extracted.

\section{Introduction}

Production operations at many Department of Energy (DOE) sites throughout the United States have resulted in enormous quantities of stored radioactive and hazardous wastes. High level radioactive waste (HLW) $\therefore$

sludges, such as those stored in the Melton Valley Storage Tanks (MVSTs) at ORNL, were formed when acidic waste streams were concentrated by evaporation of water, neutralized with caustic to precipitate many of the metals from solution, and further concentrated by additional evaporation of the water. These processes resulted in stored wastes comprised of two distinct phases; a high-pH, nitrate-bearing supernatant, and a precipitated, actinides-bearing sludge (or in some cases, saltcake). Sludges contain most of the transuranium (TRU) elements, along with other radionuclides such as rare earths, cobalt, cesium, and strontium. The radioactive components represent only a small fraction of the sludge. However, wastes containing TRU components contributing ionizing radiation of more than $100 \mathrm{nCi} / \mathrm{g}$ must be considered TRU-waste requiring expensive disposal methods (typically immobilization in deep geologic repositories [Moghissi et al., 1986]). If these radioactive components could be removed and concentrated, then the bulk of the waste would become non-TRU and suitable for near-surface disposal. Large reductions in the amount of high level waste could greatly reduce the cost of ultimate disposal of the stored wastes.

The focus of this experimental program was to evaluate the transuranium extraction (TRUEX) solvent extraction process for partitioning actinides from actual dissolved HLW sludge. A large sludge sample was removed from MVST W-25 and has been well-characterized by Collins et al. $(1995,1997)$. Portions of this 
sludge were prepared and dissolved for use in the evaluation tests. Batch liquid-liquid equilibrium tests of both the extraction and stripping operations were conducted. Chemical analyses of both phases were used to evaluate the distribution of selected components. Additional information on the dissolution of MVST sludge and on the gelation of the resulting solutions was obtained as part of the preparation for the extraction tests.

\section{Literature Review}

\section{TRUEX Process}

The TRUEX process is a solvent extraction process for recovering actinides from acidic nuclear waste streams (Horwitz and Schulz, 1990). TRUEX solvent is a mixture of octyl(phenyl)-N,Ndiisobutylcarbamoylmethyl phosphine oxide (CMPO) and tri-n-butyl phosphate (TBP) in an organic diluent. When the diluent is a normal paraffin hydrocarbon (NPH), such as $n$-dodecane, the concentrations of CMPO and t.

TBP are typically $0.2 \mathrm{M}$ and $1.4 \mathrm{M}$, respectively. CMPO is capable of extracting trivalent, as well as tetravalent and hexavalent, species (Horwitz et al., 1982). Even though TBP is an extractant for tetravalent and hexavalent actinides, it is not as powerful an extractant as CMPO. Because it ameliorates the formation of a second, heavy organic phase, TBP is considered a phase modifier in this system.

Dissolution of tank-stored wastes in nitric acid produces a solution similar to those for which TRUEX was developed. Differences occur because some stored wastes were produced by processes other than the Plutonium-Uranium Extraction (PUREX) process and because various materials were added to precipitate the waste components. Recent tests of the TRUEX process to demonstrate removal of actinides from waste streams have been reported by Ozawa et al. (1992), Mathur et al. (1993), Koma et al. (1993), and Lumetta et al. (1994).

\section{Generic TRUEX Model}

The Generic TRUEX Model (GTM) was developed at Argonne National Laboratory (ANL) as a design tool to develop TRUEX flowsheets (Vandegrift et al., 1993, Leonard et al., 1994). It is a thermodynamic model based on mass action equations that describe the equilibrium between ionic species in the aqueous phase and neutral complexed species in the organic phase. The thermodynamic equilibrium constants for the mass action equations are based on equilibrium distribution measurements made on pure component systems. The 
multicomponent aqueous phase is quite non-ideal and the activity of each species in solution is modeled by the ion interaction approach of Bromley $(1972,1973)$. The GTM is implemented as a computer program written in the macro language of Microsoft Excel ${ }^{\mathrm{TM}}$ and performs several types of calculations which can be selected by the user. It is a computing tool to aid in the development of chemical process flowsheets, and in estimating the size and cost of a processing facility. In this work it was used to model a series of ideal equilibrium batch contacts.

\section{Data on MVST W-25 Sludge Used in these Tests}

Detailed analytical data on MVST W-25 sludge solids and supernatant are available in reports by Collins et al. (1997) and Collins et al. (1995), respectively. Overall properties of the sludge and entrained supernatant include (I) air-dried solids content of centrifuged wet solids, $0.590 \mathrm{~g} / \mathrm{g}$; (2) air-dried solids content of supernatant $\therefore$

liquid, $0.285 \mathrm{~g} / \mathrm{g}$; (3) density of centrifuged wet solids, $1.53 \mathrm{~g} / \mathrm{mL}$; (4) density of supernatant, $1.206 \mathrm{~g} / \mathrm{mL}$;

(5) volume ratio of decanted supernatant to wet solids, 1:1; and (6) $\mathrm{pH}$ of supernatant, 13. Available data also includes the concentration of the primary cations and anions (except $\mathrm{OH}^{-}$) in both the supernatant and sludge phases. From this data and mass balances it is easy to estimate that $1 \mathrm{~kg}$ of centrifuged wet solids contain $475 \mathrm{~mL}$ of interstitial supernatant and that water comprises $408 \mathrm{~g}$ of that liquid.

Selection of a dissolution procedure to prepare MVST W-25 sludge for the TRUEX tests was based on four different leaching and dissolution tests reported by Collins et al. (1997). Two of these tests included leaching the sludge with caustic solution prior to dissolution with strong nitric acid $(\sim 6.0 M)$, one treatment was done with strong nitric acid $(6.0 M)$ alone, and one treatment was done with strong nitric acid $(5.8 M)$ mixed with hydrofluoric acid $(1.0 \mathrm{M})$. Within 10 percentage points, the amount of solids dissolved in each case was $70 \%$ by mass. Additionally, almost all the americium and curium, and about half the plutonium was leached from the solids. In one test $\sim 90 \%$ of the uranium was leached from the solids with $3.0 \mathrm{M}$ nitric acid. Pre-treatment with caustic or addition of hydrofluoric acid to the nitric acid dissolution primarily increased the cumulative amounts of cesium removed from the sludge. 
The amount of nitric acid required to dissolve the solids depends on the equivalents of base stored in the solids, the base in the interstitial supernatant, and the final acid concentration desired. Using two independent methods, Spencer et al. (1997b) estimated the equivalents of base stored in the sludge from the experimental data reported by Collins et al. (1997). First, from overall dissolution data and with the assumption that the hydroxide content of the interstitial supernatant was insignificant (reasonable since the $\mathrm{pH}$ is 13 ), the number of equivalents for air-dried solids were computed to be $5.98 \mathrm{~mol} / \mathrm{kg}$. Second, under the assumption that the difference in charge balance between the measured anions and cations in the sludge solids was made up by the unmeasured hydroxide ion, the hydroxide content of the air-dried sludge was estimated at $5.5 \mathrm{~mol} / \mathrm{kg}$. These numbers are quite close and may be used in estimates of the amount of acid required to dissolve the sludge.

\section{Description of Experiments \\ Reagents}

Reagent grade nitric acid, sodium hydroxide, sodium nitrate, sodium carbonate, oxalic acid, TBP, and anhydrous $n$-dodecane were purchased and used as received. Washing, leaching, stripping and other aqueous solutions were prepared by dilution with pure water and were titrated as required to verify concentration. CMPO was purchased from ATOCHEM North America, Philadelphia, $\mathrm{Pa}$., and was purified as previously reported by Spencer et al. (1997a). TRUEX solvent was prepared by dissolving weighed quantities of CMPO and TBP in $n$-dodecane to produce a solution of $0.2 \mathrm{MCMPO}$ and $1.4 \mathrm{MTBP}$. The solvent was washed twice with $0.25 \mathrm{M}$ $\mathrm{NaCO}_{3}$ solution using an organic:aqueous phase ratio of 2:1, each time discarding the aqueous phase. Then, using the same procedure, the TRUEX solvent was washed twice with $0.1 \mathrm{MHNO}_{3}$, followed by two washes with ultra pure water.

\section{Procedures}

In previously reported work, Collins et al. (1995), approximately $5 \mathrm{~L}$ of sludge/supernatant was retrieved from MVST W-25 and stored until needed in a stainless steel tank. Working in a hot-cell, sludge aliquots were dispensed from the tank and were centrifuged at $4140 \mathrm{G}$ (where $\mathrm{G}$ is equal to the gravitational acceleration at the surface of the earth) for 20 min to separate the sludge solids and supernatant. The supernatant phase was. 
decanted and saved, and the sludge solids were weighed. Because the supernatant contains a high nitrate concentration and a significant fraction of the radioactive cesium, the sludge was washed with a volume of mild caustic solution $(0.20 \mathrm{M} \mathrm{NaOH})$ equal to or exceeding the estimated interstitial supernatant volume remaining with the solids to remove these components without dissolving the actinides. At this point the dissolution procedure for the two test campaigns varied.

In the first campaign $179.1 \mathrm{~g}$ of sludge was washed with $104 \mathrm{~mL}$ of mild caustic, the mixture centrifuged, and the liquid decanted. This washing was repeated twice. The sludge was then dissolved using $362 \mathrm{~mL}$ of $5.44 M \mathrm{HNO}_{3}$.

In the second campaign $30.8 \mathrm{~g}$ of sludge was "neutralized" by adding $20 \mathrm{~mL}$ of $5.44 \mathrm{MHNO}_{3}$ to destroy hydroxides and carbonates. To this mixture was added $25 \mathrm{~mL}$ of $6.27 \mathrm{MNaOH}$, resulting in an $\sim 2.6 \mathrm{MNaOH}$ leaching solution which was mixed for $6 \mathrm{~h}$. The mixture was centrifuged and the strong caustic solution decanted. The sludge was washed twice with $50 \mathrm{~mL}$ of mild caustic. Finally the sludge was dissolved using $215 \mathrm{~mL}$ of 2.7 $\mathrm{MHNO}_{3}$ and allowed to age for about one week.

For both campaigns the undissolved solids were dried at room temperature and weighed. Aliquots of the solution containing the dissolved sludge were taken for chemical analysis.

After the washing and dissolution operations, the dissolved sludge was less radioactive and could be handled in a chemical hood. Dissolved sludge solution was filtered with $0.45 \mu \mathrm{m}$ porosity syringe filters; but in the first test the syringe filter plugged almost immediately, presumably due to a rapidly forming gel. Solutions that could not be filtered with the syringe filter were successfully filtered with no. 588 coarse, fluted filter paper. In each of the two test campaigns, four separate equi-volume equilibrations were performed to simulate four stages of a batch, cross-flow TRUEX process. Temperature was maintained at $24^{\circ} \mathrm{C}$. Filtered solution was contacted with TRUEX solvent in separatory flasks and shaken by hand for at least $60 \mathrm{~s}$. The aqueous and organic phases were then allowed to separate by gravity for $15 \mathrm{~min}$. Each phase was sampled for chemical analysis. Similar procedures were used for any subsequent extraction steps and for aqueous stripping of the loaded organic phase. In the first extraction stage of the first test a third phase formed. Adding fresh solvent to 
increase the organic to aqueous phase ratio to $2.5: 1$ eliminated the third phase. Figures 1 and 2 illustrate the contacting patterns and reagents used at each equilibrium stage.

\section{Analyses of samples}

Generally the analytical procedures used for the aqueous and organic samples were the same, but analysis of metals in the organic medium first required destruction of the organic matrix with a microwave acid digestion using a combination of sulfuric and nitric acids to place the analytes in aqueous solution. Acid concentration was measured using potentiometric titration with $0.100 \mathrm{M} \mathrm{NaOH}$ solution. Metals were analyzed with Inductively Coupled Plasma - Atomic Emission Spectroscopy (ICP-AES). Ion chromatography was used to measure the concentration of the common ions (e.g. fluoride, chloride, bromide, nitrate, phosphate and sulfate). Alpha spectroscopy was used to measure the amounts of the transuranium elements ${ }^{239} \mathrm{Pu},{ }^{241} \mathrm{Am}$ and ${ }^{244} \mathrm{Cm}$ in a sample. Gamma-emitting nuclides, such as ${ }^{137} \mathrm{Cs}$ and ${ }^{154} \mathrm{Eu}$, were measured with gamma spectroscopy. Strontium was isolated by extraction chromatography to reduce interferences prior to radiocounting. Turbidity in aqueous sludge leachates and extraction raffinates was measured with a Hach 2100 AN Turbidimeter as described previously by Beahm et al. (1997).

\section{Results and Discussion}

\section{Dissolution of MVST Sludge}

Dissolution of the sludge in the first campaign resulted in a solution having a cation concentration (not including $\mathrm{H}^{+}$) of $\sim 1.8 \mathrm{M}$ and an $\mathrm{HNO}_{3}$, concentration of $2.9 \mathrm{M}$. On the basis of air-dried sludge and residue, only $54.4 \%$ of the sludge dissolved. Because the objective was to test the TRUEX process, the residue was not analyzed. However, the dissolved sludge solution was well characterized. A calculation was made based on the sludge characterization data of Collins et al. (1997) to estimate the concentration of each species in dissolved sludge under the assumptions that all the sludge dissolved and the volume of the acid solution did not change during dissolution. The estimated concentrations are compared with those actually measured in the solution in Table 1. The ratio of the calculated concentration to the measured concentration simplifies comparison of the data. Values of the ratio near unity indicate those species that dissolved completely. Small variations around 
unity (say \pm 0.20 ) are attributed to the assumptions on which the calculations were made. Larger values are taken to indicate those species that dissolved sparingly. From these results the undissolved solids are inferred to contain a large fraction of the initial $\mathrm{Cs}, \mathrm{Pu}, \mathrm{Na}, \mathrm{Si}, \mathrm{Sr}, \mathrm{Tl}, \mathrm{PO}_{4}{ }^{3-}$, and $\mathrm{SO}_{4}{ }^{2-}$. Most of the other metals including the rare earths and actinides dissolved almost completely.

In the second campaign the dissolution procedure resulted in a solution having a cation concentration (not including $\mathrm{H}^{+}$) of $\sim 0.6 \mathrm{M}$ and a $\mathrm{HNO}_{3}$ concentration of $1.7 \mathrm{M}$. On the basis of air-dried solids, $79.3 \%$ of the sludge dissolved even though weaker nitric acid was used. The improved dissolution is thought to be the result of a combination of preleaching the solids with $2.6 \mathrm{M}$ caustic and using a larger liquid to solids ratio. The effect of neutralizing the sludge with nitric acid to destroy the carbonates may have improved the effectiveness of the caustic preleach. Again a calculation was made to estimate the concentration of each species in the solution assuming that the sludge completely dissolved in the nitric acid. No credit was taken in the calculation for species that may have been removed by the caustic leaching. The estimated and actual concentrations in the dissolved sludge solution, and the ratio of the two, are shown in Table 2 . The ratio is significantly greater than unity for those species that were either removed by the caustic preleaching or undissolved. Species fitting this description include $\mathrm{Cs}, \mathrm{Pu}, \mathrm{Sr}, \mathrm{PO}_{4}^{3-}$, and $\mathrm{SO}_{4}{ }^{2-}$. In the second test, the concentration of species that originate from the sludge should, assuming all the sludge dissolved in the nitric acid, be about one-third of the concentration obtained in the first test. Comparing the measured concentration of silicon and phosphate between Tables 1 and 2 indicates that silicon was made much more soluble in the second dissolution procedure and that phosphate was likely removed by the caustic preleach. Similarly, strontium was removed in the preleach. The caustic in the preleach was not strong enough to solubilize plutonium, so the data indicate that much of it remains with the undissolved residue.

\section{Gelation of Dissolved Sludge}

Immediately after the sludge was dissolved, the solution was filtered. Dissolved sludge solution from the first campaign could not be filtered with $0.45 \mu \mathrm{m}$ porosity syringe filters because the filters plugged almost immediately. The solution was filtered with no. 588 coarse filter paper and a small amount of gel-like residue 
could be observed on the filter. Following filtering the solution was hazy. Turbidity measurements were made over a period of several days. The data are shown in Figure 3. In eight days a visible layer of gel formed and in about 20 days the sample was almost completely gelled as shown in Figure 4.

Solution from the second campaign was successfully filtered with the syringe filters, but with some difficulty. The sample was initially clear, but became hazy in 8 days. Gellation did not occur after 20 davs. Measured values of turbidity are shown in Fig. 3 to permit direct comparison to the results from the first campaign. The difference is quite marked. Table 3 summarizes the dissolution and gel formation characteristics observed in the two campaigns.

Aqueous raffinate samples from the first extraction stage of each campaign were also set aside for observation. Both visual observation and measured turbidity followed the same pattern as did the dissolved sludge solution.

\section{TRUEX Partitioning of Dissolved Sludge}

The generic TRUEX model (GTM) was used to simulate the batch shake-out tests, and model predictions were compared to measured results. Because the test temperature of $24^{\circ} \mathrm{C}$ was close to $25^{\circ} \mathrm{C}$, the temperature at which the GTM data base is more complete, that value was used for all simulations. Measured dissolved sludge compositions were used to describe the aqueous feed stream. Because the GTM does not include all species found in the sludge, species from the same periodic group were assumed to behave similarly and were lumped as follows: (1) $\mathrm{Tl}$ with $\mathrm{Al}$, (2) $\mathrm{Co}$ and $\mathrm{Ni}$ with $\mathrm{Fe}$, (3) $\mathrm{K}$ with $\mathrm{Na}$, (4) Be with $\mathrm{Mg}$, (5) $\mathrm{Mn}$ with $\mathrm{Tc}$, (6) $\mathrm{Zn}$ and $\mathrm{Hg}$ with $\mathrm{Cd}$, and (7) $\mathrm{Br}$ and $\mathrm{Cl}$ with $\mathrm{F}$. This allows the model to estimate the appropriate total anion concentrations. The elements $\mathrm{Pb}, \mathrm{Si}$, and $\mathrm{V}$ were not as easily generalized, but because the concentrations were small and they should not extract appreciably, they were ignored. Carbonate was assumed to be evolved from the solutions as $\mathrm{CO}_{2}$ during the dissolution and was set to zero in the simulations. All $\mathrm{Pu}$ was assumed to be in the +4 valence state. The fractions of each phase entrained in the other phase were set to zero and fractional efficiencies for each stage were set to unity. The GTM uses the composition and volume of the aqueous and organic feed solutions to calculate the distribution ratios and equilibrium concentrations in both phases for each species. When the 
effluent from one stage becomes the feed to another stage, the computed concentrations are passed on as input to the subsequent calculation.

First Campaign. As illustrated in Fig. 1, the first TRUEX campaign consisted of two extraction and two strip steps. Experimental values of the percentage of each component extracted from the dissolved sludge solution were calculated from the aqueous concentrations measured before and after extraction. Results of the GTM simulation were converted to predicted values by combining the calculated distribution ratios with the organic-toaqueous phase ratio. That is,

$$
r_{i, e x t}=\left(\frac{\left(V_{o r g} / V_{a q}\right) D_{i}}{\left(V_{o r g}^{k} / V_{a q}\right) D_{i}+1}\right) \times 100
$$

where $r_{i, \text { ext }}$ is the percentage of species $i$ removed by the first extraction stage, $D_{i}$ is the distribution ratio for species $i, V_{o r g}$ is the organic phase volume, and $V_{a q}$ is the aqueous phase volume. The predicted and measured values for the first extraction stage are compared in Table 4 for selected components. The extent of extraction was $97 \%$ for $\mathrm{Eu}, 99 \%$ for Th, $99+\%$ for $\mathrm{U}, 99 \%$ for $\mathrm{Pu}$, and $96 \%$ for $\mathrm{Cm}$. Concentrations of Am were below the reliable reporting limit. Iron, calcium, strontium, and cesium essentially did not extract. Model predictions are consistent with these results. Cadmium was not expected to extract, but the data indicate that a small quantity extracted. The data indicate that mercury was strongly extracted, with $93 \%$ removal. Similar reductions in the aqueous phase concentrations of the actinides in the second extraction stage could not be verified experimentally because (1) the remaining concentrations were so low as to make discrimination in the analyses difficult, and (2) it is likely that microscopic gelation sites formed that immobilized some of the constituents in the aqueous phase thereby preventing their extraction.

The loaded organic from the first extraction stage was subjected to two sequential aqueous strips. Stripping with mild nitric acid $\left(0.01 \mathrm{MHNO}_{3}\right)$ and sodium nitrate $\left(0.5 \mathrm{MNaNO}_{3}\right)$ removed some of the nitric acid from the organic phase, but little of the actinides or europium were recovered. The GTM accurately predicted this result. The second strip was done with an aqueous solution of mild nitric acid and oxalic acid 
$\left(0.5 \mathrm{M} \mathrm{H}_{2} \mathrm{C}_{2} \mathrm{O}_{4}\right)$. A white precipitate was observed to form in the aqueous phase. Analysis of filtered organic samples indicated that Eu was stripped from the organic to the extent of $>99 \%, \mathrm{Am} 96 \%$, Th $98 \%, \mathrm{Hg} 50 \%$, and U only $20 \%$. The low stripping and recovery factors for uranium indicate that either more stripping stages or a more effective stripping agent is required. It also makes separation of uranium from the other actinides appear to be an attractive option. The iterative numerical methods of the GTM would not converge at the second stripping stage where the precipitate formed.

Second Campaign. The second TRUEX campaign included one extraction and three consecutive strip steps (see Fig. 2). Aqueous phase samples were taken from each of the four individual contacts. Organic phase samples were taken from the extraction stage (stage 1) and the last strip stage (stage 4). The organic phases from stages 2 and 3 were not sampled because stripping with mild nitric acid $(0.01 M)$ would not effectively recover a large fraction of the actinides unless the organic phase acid concentration was first reduced. No precipitates formed in any of the stages and gelation was not as evident as in the first campaign.

Again, the experimentally measured percentages of selected species extracted from the aqueous dissolved sludge solution are compared to values predicted by the GTM in Table 5. One stage of extraction removes $93 \%$ of the Eu, $>99 \%$ of the $\mathrm{Th},>99 \%$ of the $\mathrm{U}, 99 \%$ of the $\mathrm{Pu}$, and $>77 \%$ of the Am. Calcium, strontium, cesium, chromium, and iron were not extracted - a positive result since TRUEX does not target these metals. The model indicates that $\mathrm{Cd}$ is not extracted and the data corroborate this. However, $95 \%$ of the $\mathrm{Hg}$ and $42 \%$ of the $\mathrm{V}$ were extracted.

Based on measured aqueous phase concentrations, stripping with mild nitric acid recovered $93 \%$ of the Eu and $99 \%$ of the Am in three stages. Eu and Am were mostly recovered in the first two stripping stages, $81 \%$ and $80 \%$, respectively, indicating that they were easily stripped. Pu was more difficult to strip, with little being recovered until the third stripping stage where $50 \%$ was recovered. Th and $U$ also began to transfer from the organic at the third stripping stage. The concentrations of mercury and vanadium, being at or below the detectable limit in the aqueous strip solution, did not permit definitive conclusions regarding their stripping behavior. 
The predicted concentration profiles of europium, uranium, plutonium and americium are compared to the experimental data in Figs. 5 through 8. Error bars around the experimental data points are based on the variance between two replicate analyses. Large error bars occur where the measured concentration is at or below the detectable limit, and the model may be expected to vary from the data at these points. In many instances the error bars do not extend beyond the data markers. Concentrations of Eu and Am are higher in the second strip (3rd stage) than in the third strip (4th stage) indicating the relative ease of recovery as described above. $U$ and $\mathrm{Pu}$ are more difficult to strip as indicated by the high concentrations remaining in the organic after the third strip. The predicted plutonium concentrations in the aqueous phase are uniformly lower than the experimental data. There are five reasons why this might occur: (1) the measured plutonium concentration in the starting dissolved sludge solution could be too low, which cascades through the calculations to subsequent stages, (2) at the low $\therefore$.

concentrations of the test the analysis method over-estimates the plutonium concentration, (3) the model over-estimates the distribution ratio, (4) microscopic gel particles may bind a fraction of the plutonium preventing extraction, or (5) a small fraction of organic phase was entrained in the aqueous phase. The last two seem the most likely. Generally the agreement between the model and data is quite good.

\section{Summary}

On a dry weight basis, about half of the sludge from MVST Tank W-25 dissolves in $5.5 \mathrm{M}$ nitric acid. Silicon, phosphate and cesium are the primary constituents that do not dissolve. About half of the plutonium dissolves, but the other actinides dissolve more readily. Neutralizing the sludge with nitric acid (which destroys hydroxides and carbonates) followed by leaching with $2.6 \mathrm{M}$ caustic prior to final acid dissolution results in $\sim 80 \%$ of the sludge being dissolved. The second dissolution where the sludge was pre-leached with caustic, and where the total cation and acid concentrations were lower ( $0.6 M$ vs $1.8 M$ and $1.7 M$ vs $2.9 M$, respectively) resulted in large decreases in the rate of gel formation and the quantities of gel formed. Additional work needs to be performed to ascertain the causal mechanism.

The bulk of the actinides are readily extracted from dissolved sludge solutions with the TRUEX process, even at low acidity $(\sim 0.6 M)$. However, formation of gels appears to raise the lower limits of concentration that 
can be achieved in the aqueous phase. In spite of difficult process conditions (e.g. gels), the Generic TRUEX Model does a good job in predicting the removal and recovery of the actinides.

Caustic leaching prior to acidic dissolution should be investigated further to (1) ascertain and quantify' the effects on gel formation and (2) evaluate the reduction such a two-step process achieves in the ultimate quantities of $\mathrm{HLW}$ requiring vitrification. Cation concentration may also affect gel formation. The quantities of mercury and vanadium in the waste should be evaluated to ascertain whether the extraction characteristics of these metals should be quantified and added to the GTM. Additives, such as fluoride, to inhibit gel formation should be evaluated with respect to both gel formation and the effect on the TRUEX process.

\section{Acknowledgments}

This work was sponsored by the U. S. Department of Energy's Office of Science and Technology-Tank Focus Area under U. S. Government contract DE-AC05-96OR22464 with Lockheed Martin Energy Research Corp. The work was performed at the Oak Ridge National Laboratory under the auspices of the Chemical Technology Division. The Chemical and Analytical Services Division performed the chemical analyses of samples.

\section{Literature Cited}

Beahm, E. C., C. F. Weber, T. A. Dillow, S. A. Bush, S. Y. Lee, and R. D. Hunt, "Sludge Treatment Studies," ORNL/TM-13371, Lockheed Marietta Energy Research, Oak Ridge National Laboratory, June 1997.

Bromley, L. A., "Approximate Individual Ion Values of $\beta$ (or B) in Extended Debye-Hückel Theory for UniUnivalent Aqueous Solutions at 298.15 K," J. Chem. Thermodyn., 4, 669-673, 1972.

Bromiey, L. A., "Thermodynamic Properties of Strong Electrolytes in Aqueous Solutions," AIChE J., 19(2), 313 320, March 1973.

Collins, J. L., B. Z. Egan, K. K. Anderson, C. W. Chase, J. E. Mrochek, J. T. Bell, and G. E. Jernigan, "Evaluation of Selected Ion Exchangers for the Removal of Cesium from MVST W-25 Supernate," ORNL/TM12938, Martin Marietta Energy Systems, Oak Ridge National Laboratory, April 1995.

Collins, J. L., B. Z. Egan, E. C. Beahm, C. W. Chase, and K. K. Anderson, "Characterization and Leaching Study of Sludge from Melton Valley Storage Tank W-25," ORNL/TM-13445, Lockheed Marietta Energy Research, Oak Ridge National Laboratory, in publication, 1997. 
Horwitz, E. P., D. G. Kalina, L. Kaplan, G. W. Mason, and H. Diamond, "Selected Alkyl(phenyl)-N,Ndialkylcarbamoylmethylphosphine Oxides as Extractants for Am(III) from Nitric Acid Media," Sep. Sci. and Tech., 17(10), 1261-1279, 1982.

Horwitz, E. P. and W. W. Schulz, "The TRUEX Process: A Vital Tool for Disposal of U. S. Defense Nuclear Wastes," Conference on New Separation Chemistry for Radioactive Waste and Other Specific Applications, Rome, Italy, May 1990.

Koma, Y., K. Nomura, S. Nemoto, M. Ozawa, and T. Kawata, "Application of Modified TRUEX Flowsheet to Monitor Actinide Separation from High Level Liquid Waste," Proceedings of International Symposia on Waste Management, Tucson, Arizona, February 28 - March 4, 1993.

Leonard, R. A., D. B. Chamberlain, J. A. Dow, S. E. Farley, L. Nuñez, M. C. Regalbuto, and G. F. Vandegrift, "Basic TRUEX Process for Rocky Flats Plant," ANL-94/33, The University of Chicago, Argonne National Laboratory, August 1994.

Lumetta, G. J., B; M. Rapko, M. J. Wagner, C. D. Carlson, and R. J. Barrington, "Sludge Treatment and Extraction Technology Development: Results of FY 1993 Studies," PNL-9387, Battelle Memorial Institute, Pacific Northwest National Laboratory, March 1994.

Mathur, J. N., M. S. Murali, P. R. Natarajan, L. P. Badheka, A. Banerji, A. Ramanujam, P. S. Dhami, V. Gopalakrishnan, R. K. Dhumwad, and M. K. Rao, "Partitioning of Actinides from High-Level Waste Streams of PUREX Process Using Mixtures of CMPO and TBP in Dodecane," Waste Management, 13, 317-325, 1993.

Moghissi, A. A., H. W. Godbee, and S. A. Hobart, Radioactive Waste Technology, The American Society of Mechanical Engineers, New York, 1986.

Ozawa, M., S. Nemoto, A. Togashi, T. Kawata, and K. Onishi, "Partitioning of Actinides and Fission Products in Highly-Active Raffinate from PUREX Process by Mixer-Settlers," Solvent Extr. Ion Exch., 10(5), 829-846, 1992.

Spencer, B. B., R. M. Counce and B. Z. Egan, "Extraction of Nitric Acid from Aqueous Media with O $\phi \mathrm{D}(\mathrm{iB}) \mathrm{CMPO}-n$-Dodecane," AlChE J., 43(2), 555-564, 1997a.

Spencer, B. B., B. Z. Egan, and C. W.Chase, "Removal of Actinides from Dissolved ORNL MVST Sludge Using the TRUEX Process," ORNL/TM-13475, Loçkheed Martin Energy Systems, Oak Ridge National Laboratory, July, $1997 \mathrm{~b}$.

Vandegrift, G. F., D. B. Chamberlain, C. Conner, J. M. Copple, J. A. Dow, L. Everson, J. C. Hutter, R. A. Leonard, L. Nuñez, M. C. Regalbuto, J. Sedlet, B. Srinivasan, S. Weber, and D. G. Wygmans, "Development and Demonstration of the TRUEX Solvent Extraction Process," Proceedings of International Symposia on Waste Management, Tucson, Arizona, February 28 - March 4, 1993 
Table 1. Comparison of estimated ${ }^{*}$ and measured concentrations of selected species in dissolved sludge solution for the first test.

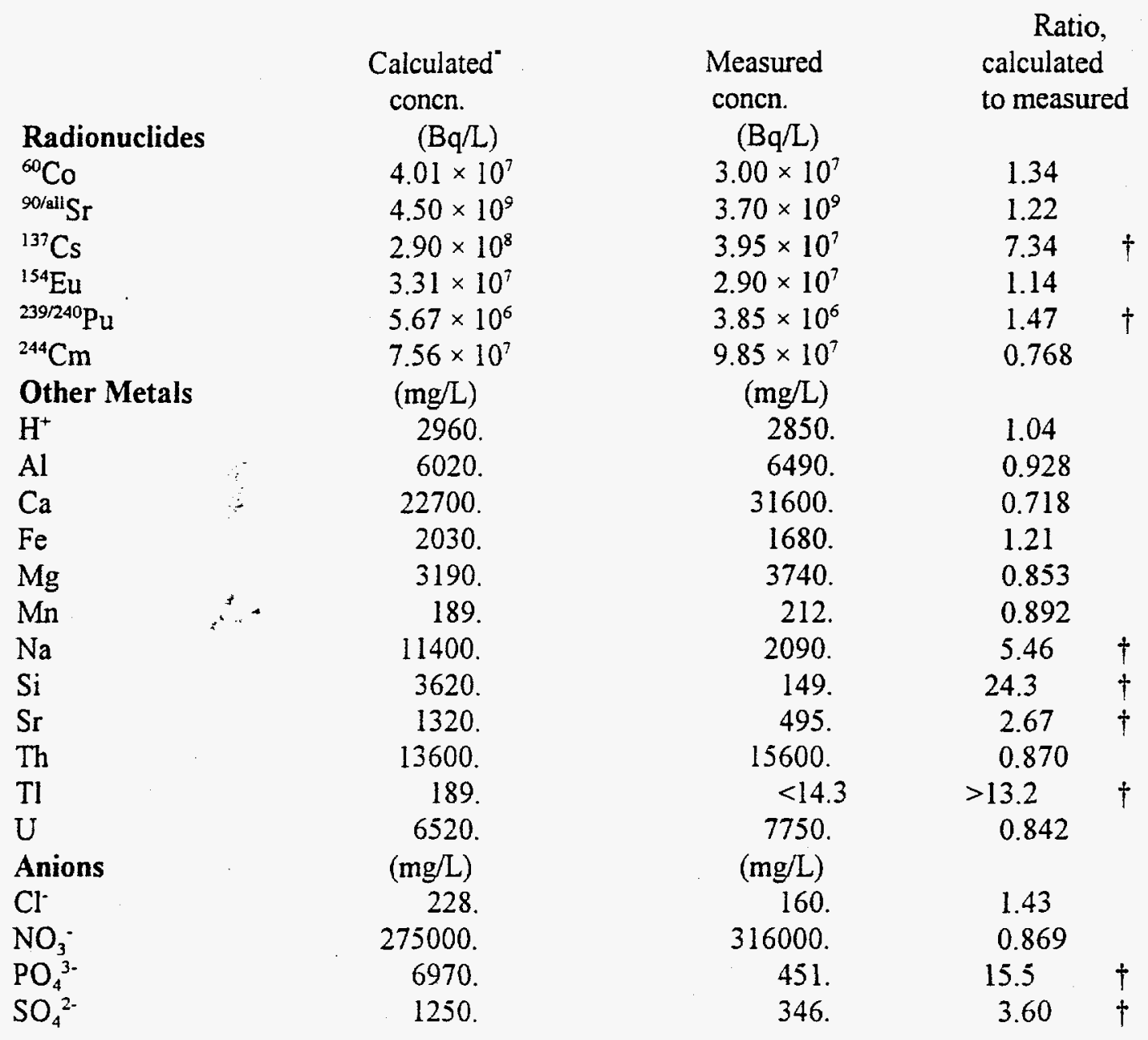

"Assumes ideal solutions and total solids dissolution.

†Components inferred to dissolve incompletely. 
Table 2. Comparison of estimated ${ }^{*}$ and measured concentrations of selected species in dissolved sludge solution for the second test.

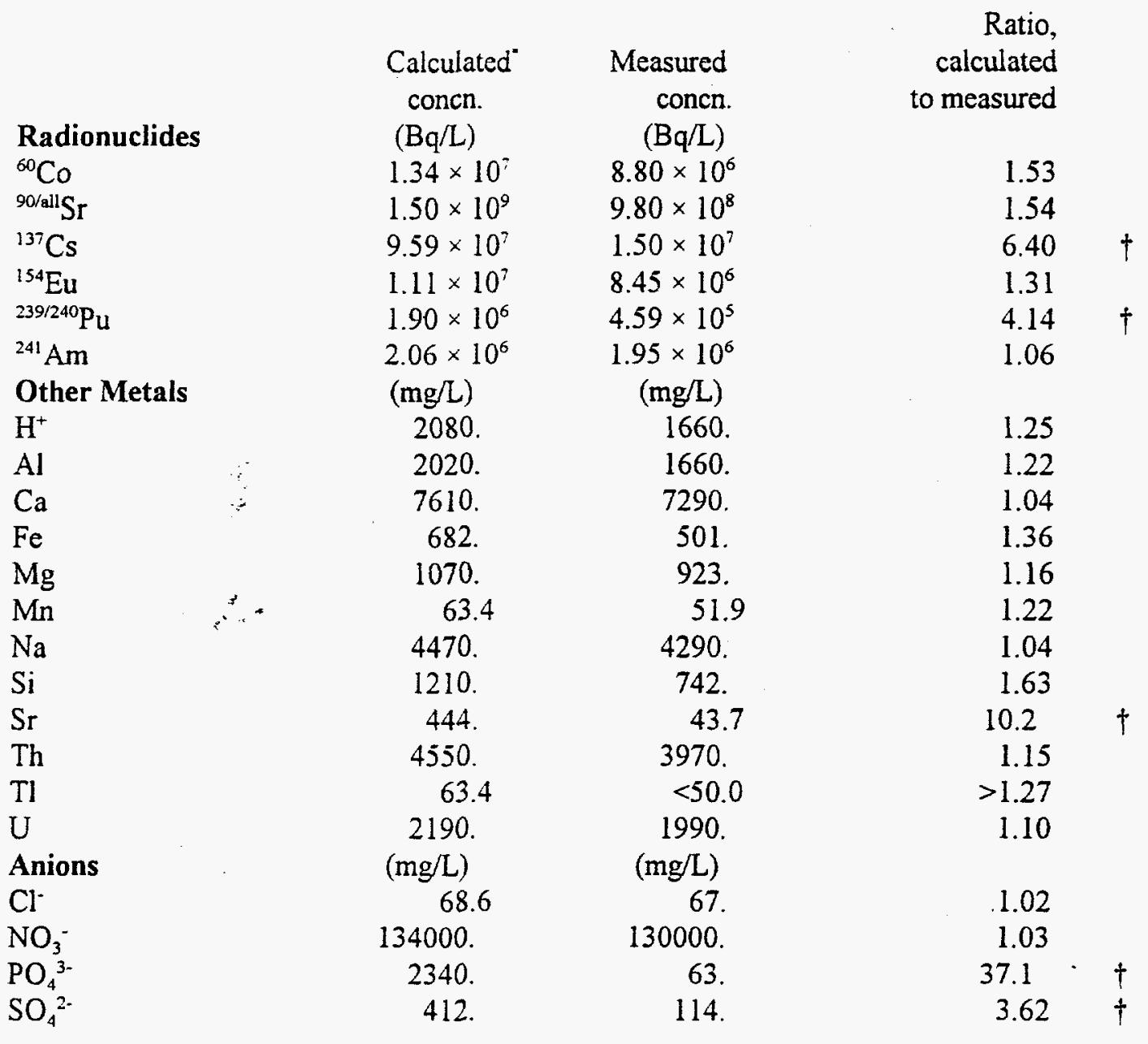

Assumes ideal solutions and total solids dissolution.

† Components inferred to dissolve incompletely or removed by caustic leaching. 
Table 3. Summary of dissolution results and effect on gel formation.

Acid Neutralization

Caustic Pre-leach

Acid Dissolution

final $\mathrm{HNO}_{3}$

final metal

solid residue

main undissolved species

$$
\text { actinides }
$$

fission products

process chemicals

\section{Gel Formation}

rate

condition at several minutes

condition at. 8 days

condition at 20 days $1^{\text {st }}$ Test

No

No

$2^{\text {nd }}$ Test

Yes

$2.6 M$

$2.9 \mathrm{M}$

$1.8 \mathrm{M}$

$46.5 \%$

$1.7 M$

$0.6 \mathrm{M}$

$20.7 \%$

$\mathrm{Pu}$

$\mathrm{Cs}, \mathrm{Sr}, \mathrm{Tl}$

$\mathrm{Na}, \mathrm{Si}, \mathrm{PO}_{4}{ }^{3-}$

$\mathrm{Pu}$

$\mathrm{Cs}, \mathrm{Sr}$

$\mathrm{PO}_{4}{ }^{3 .}$

$\begin{array}{ll}\text { rapid } & \text { slow } \\ \text { hazy } & \text { clear } \\ \text { gel layer } & \text { hazy } \\ \text { rigid gel } & \text { hazy }\end{array}$


Table 4. Fraction of selected species removed from dissolved sludge by first extraction stage of the first test and comparison of GTM predictions with measured values.

\begin{tabular}{|c|c|c|c|}
\hline \multirow[b]{2}{*}{ Metal } & \multicolumn{2}{|c|}{ GTM prediction } & \multirow{2}{*}{$\begin{array}{l}\text { Measured value } \\
\text { percent removed }\end{array}$} \\
\hline & Distribution ratio & Percent removed & \\
\hline $\mathrm{Ca}$ & 0.001 & 0.25 & 7.6 \\
\hline $\mathrm{Cr}$ & 0.001 & 0.25 & 3.7 \\
\hline $\mathrm{Fe}$ & 0.001 & 0.25 & 1.8 \\
\hline $\mathrm{Sr}$ & 0.001 & 0.25 & $-1.4^{a}$ \\
\hline $\mathrm{Cd}$ & 0.003 & 0.30 & 17.8 \\
\hline Cs & 0.001 & 0.25 & $-1.3^{b}$ \\
\hline $\mathrm{Hg}$ & Not in GTM & & 92.7 \\
\hline $\mathrm{Eu}$ & 36.97 & 98.9 & $>97.2^{\circ}$ \\
\hline Th & 4302. & $99.9+$ & 98.9 \\
\hline $\mathrm{U}$ & 1349. & $99.9+$ & $99.9+$ \\
\hline $\mathrm{Pu}$ & 1415 & $99.9+$ & $98.9^{d}$ \\
\hline $\mathrm{Am}$ & 50,65 & 99.2 & $e$ \\
\hline $\mathrm{Cm}$ & 37.48 & 98.9 & 95.5 \\
\hline
\end{tabular}

${ }^{a}$ Based on ${ }^{90} \mathrm{Sr}$.

${ }^{b}$ Based on ${ }^{137} \mathrm{Cs}$.

${ }^{6}$ Based on ${ }^{152} \mathrm{Eu}$ and ${ }^{154} \mathrm{Eu}$.

${ }^{d}$ Average of values for ${ }^{238} \mathrm{Pu},{ }^{239} \mathrm{Pu}$, and ${ }^{242} \mathrm{Pu}$.

'Insufficient data. 
Table 5. Fraction of selected species removed from dissolved sludge by extraction stage of the second test and comparison of GTM predictions with measured values.

\begin{tabular}{lccc}
\hline & \multicolumn{2}{c}{ GTM Prediction } & Measured value, \\
\cline { 2 - 4 } Metal & Distribution ratio & Percent removed & $\begin{array}{c}\text { percent removed } \\
\text { perion }\end{array}$ \\
\hline $\mathrm{Ca}$ & 0.001 & 0.10 & 0.0 \\
$\mathrm{~V}$ & Not in GTM & & 42.4 \\
$\mathrm{Cr}$ & 0.001 & 0.10 & -2.1 \\
$\mathrm{Fe}$ & 0.001 & 0.10 & 2.0 \\
$\mathrm{Sr}$ & 0.001 & 0.10 & $2.0^{a}$ \\
$\mathrm{Cd}$ & 0.004 & 0.43 & -1.8 \\
$\mathrm{Cs}$ & 0.001 & 0.10 & $-6.67^{b}$ \\
$\mathrm{Hg}$ & Not in GTM & & 95.1 \\
$\mathrm{Eu}$ & 18.66 & 94.9 & $93.2^{c}$ \\
$\mathrm{Th}$ & 5916. & $99.9+$ & 99.9 \\
$\mathrm{U}$ & 679.7 & 99.9 & 99.7 \\
$\mathrm{Pu}$ & -1457. & $99.9+$ & $99.4^{d}$ \\
$\mathrm{Am}$ & 25.56 & 96.2 & $>77.4$ \\
$\mathrm{Cm}$ & & & $e$ \\
\hline${ }^{\circ} \mathrm{Based}$ on ${ }^{90} \mathrm{Sr}$ & & &
\end{tabular}

${ }^{a}$ Based on ${ }^{90} \mathrm{Sr} .{ }^{5}$.

${ }^{6}$ Based on ${ }^{137} \mathrm{Cs}$.

${ }^{6}$ Based on ${ }^{152} \mathrm{Eu}$ and ${ }^{154} \mathrm{Eu}$.

eAverage of values for ${ }^{239} \mathrm{Pu}$ and ${ }^{242} \mathrm{Pu}$.

'Insufficient data. 


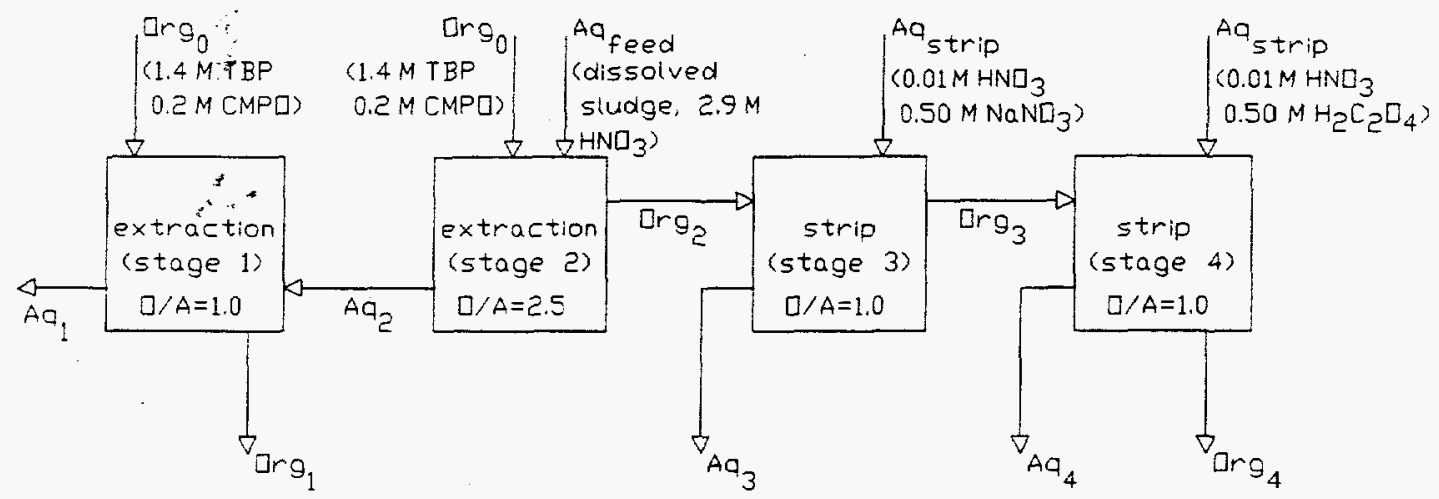

Figure 1. Material flow paths for first TRUEX test campaign. 


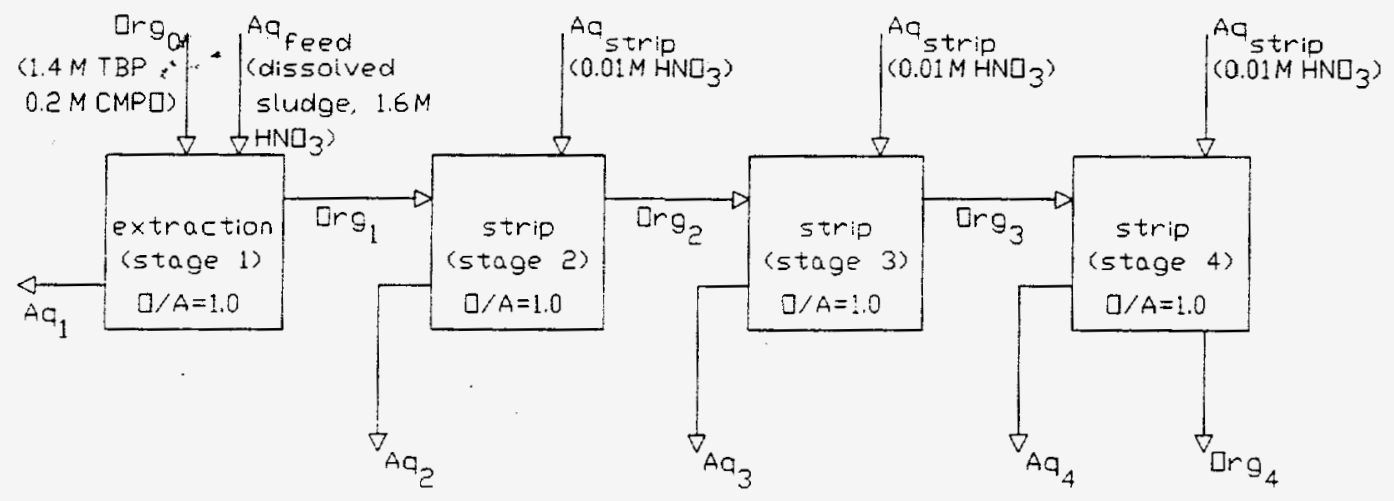

Figure 2. Material flow paths for second TRUEX test campaign. 


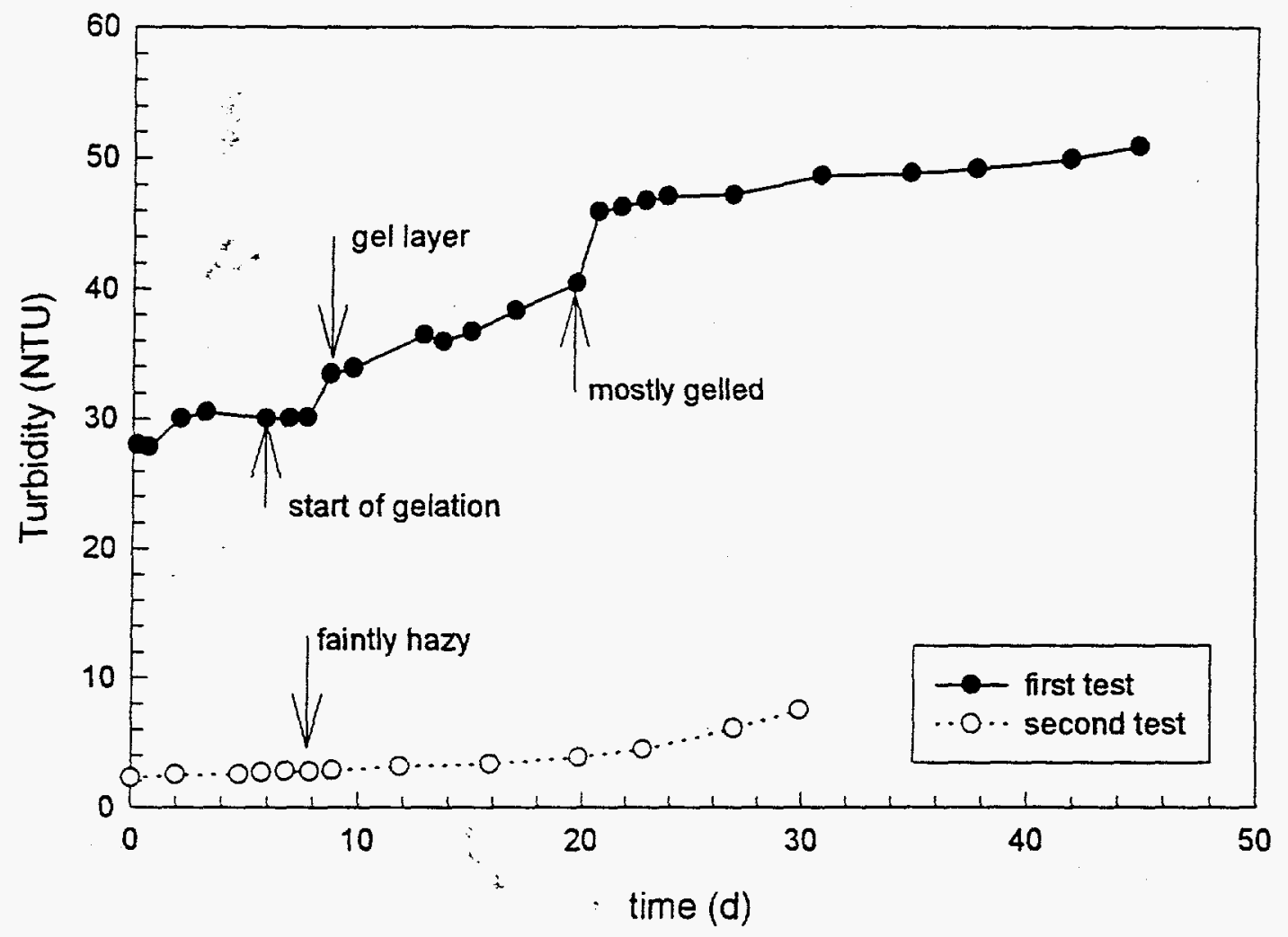

Figure 3. Turbidity of dissolved sludge solutions; comparison between the two tests. 

Eu

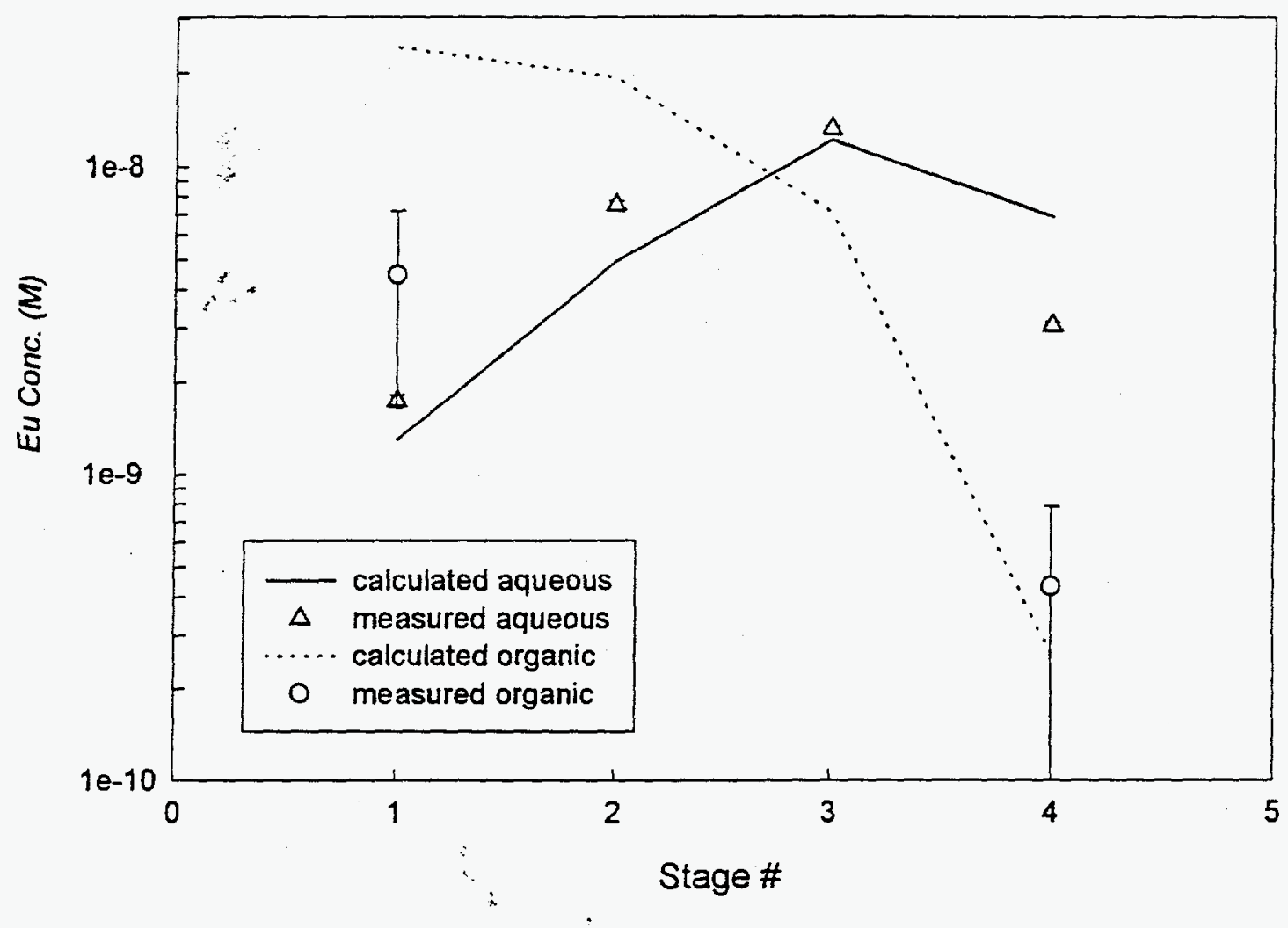

Figure 5. Comparison of measured and calculated stagewise concentration profiles for Eu. 
U

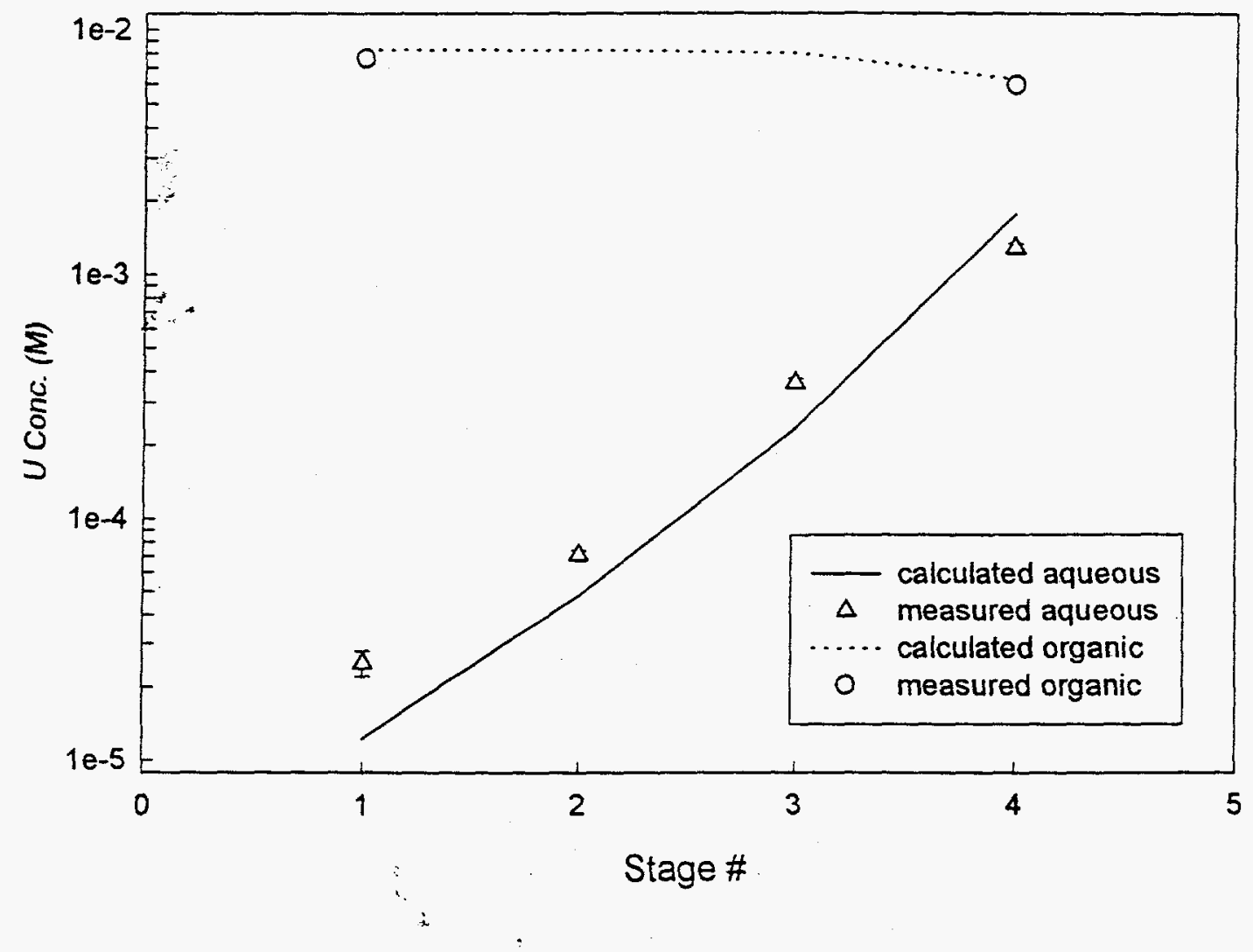

Figure 6. Comparison of measured and calculated stagewise concentration profiles for $U$. 


\section{$\mathrm{Pu}$}

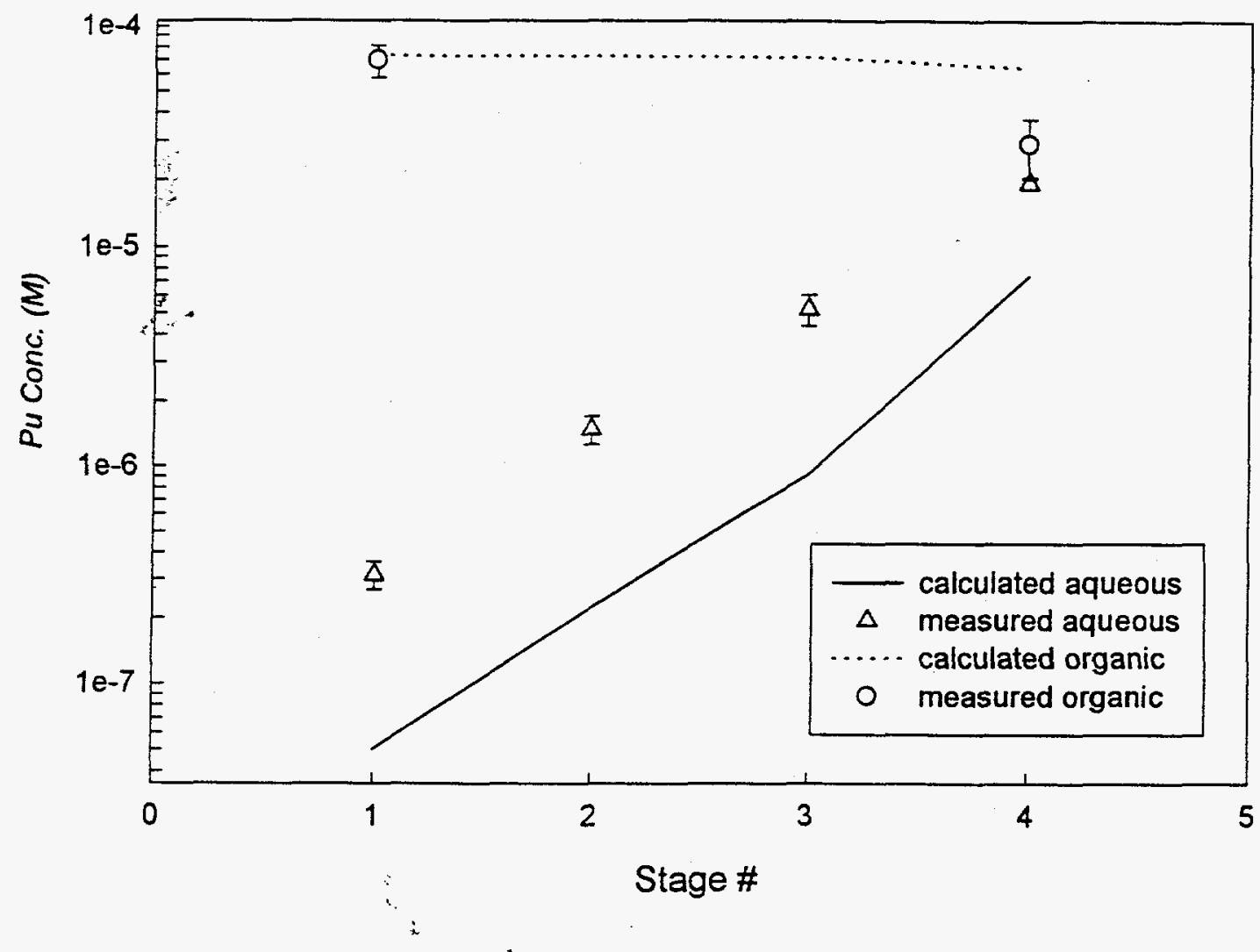

Figure 7. Comparison of measured and calculated stagewise concentration profiles for $\mathrm{Pu}$. 
Am

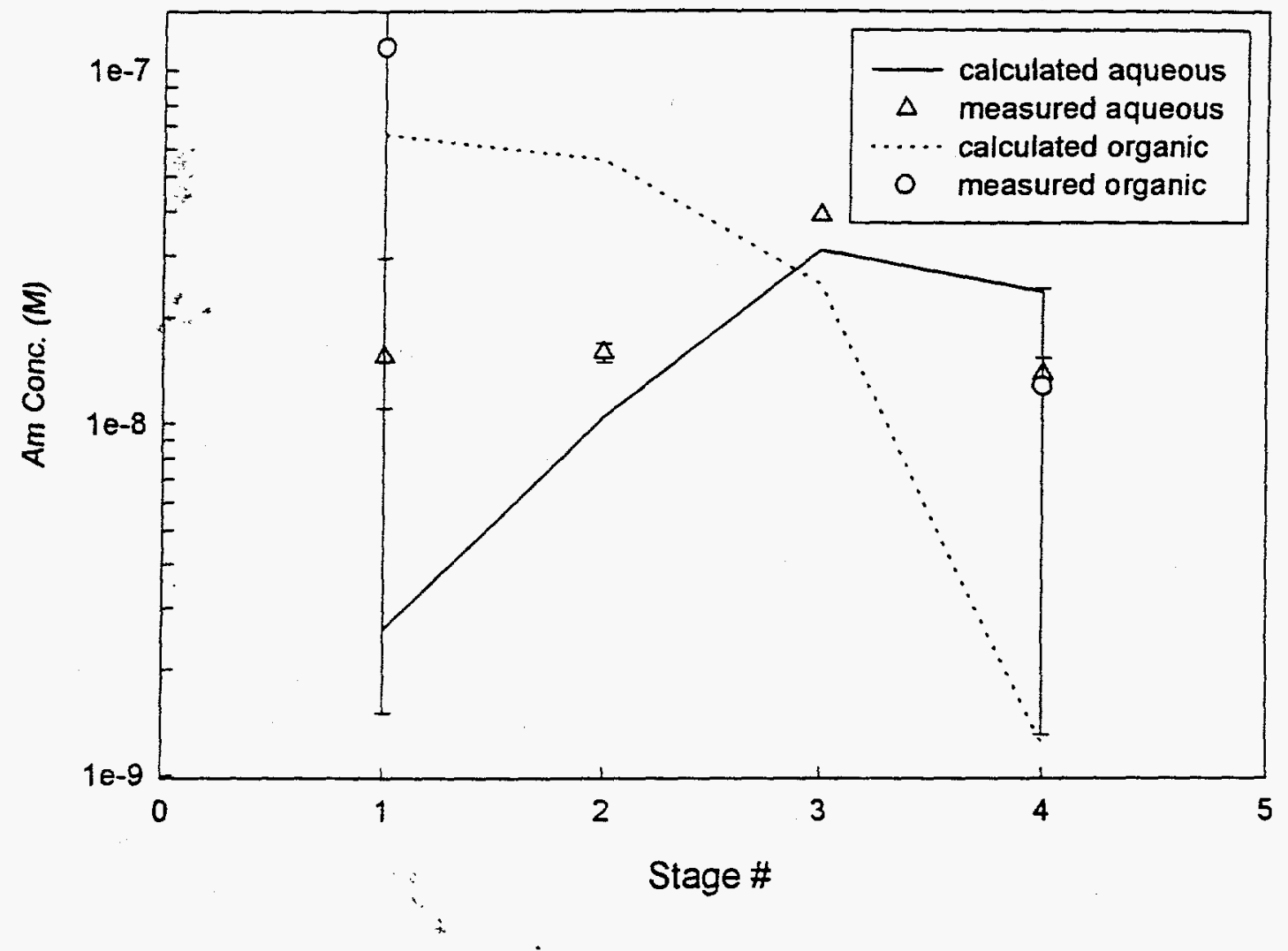

Figure 8. Comparison of measured and calculated stagewise concentration profiles for Am. 